\title{
Synergistic effect of Plant Extracts Supplemented Diets on Immunity and Resistance to Aeromonas hydrophila in Mystus keletius
}

\author{
Mrs.S.Subeena Begum ${ }^{1}$ and Dr.P.S.Navaraj ${ }^{2}$ \\ ${ }^{1}$ Assistant Professor, Dept.of Microbiology, M.S.S. Wakf Board College, Madurai. \\ ${ }^{2}$ Associate Professor, Dept.of Zoology, Yadava College, Madurai.
}

\begin{abstract}
The mixture of two plant extracts ( Solanum trilobatum and Ocimum sanctum) were extracted with $70 \%$ ethanol and screened for their antimicrobial activities against Aeromonas hydrophila, a bacterial pathogen. Using disk diffusion assays, equal proportions of plant mixture extract ( mixture of Solanum trilobatum, Ocimum sanctum in 1:1 proportion) were mixed thoroughly with the artificial feeds at concentrations of $0.0(A), 3(B), 30(C), 300(D) \mathrm{mg} \mathrm{kg}^{-1}$ of dry diet. The prepared diets were fed to healthy Mystus keletius for 60 days and then challenged with A. hydrophila. The hematological, biochemical and immunological parameters of fish were investigated at 20, 40 and 60 days of feeding and also on 10th day postchallenge in order to evaluate the immune response and resistance against A. hydrophila infection of fish. Results indicated that respiratory burst activity, serum bactericidal activity, lysozyme activity, serum protein, albumin, globulin, $W B C, R B C$ and haemoglobin content were enhanced $(p<0.05)$ in fish fed herbal diets compared to the control group. On 10 days post-challenge, the total survival rates were $38.09 \%$ in control group (A) and $72.15 \%, 80.95 \%, 85.71 \%$ in groups B, C, D respectively. Among different groups, D generally showed the best performance in the experiment. Further research is needed to isolate and characterize the active compounds from these plants.
\end{abstract}

Keywords: Aeromonas hydrophila, Immune response, Solanum trilobatum, Ocimum sanctum, bactericidal activity, lysozyme activity, Mystus keletius

\section{Introduction}

Diseases such as bacterial, fungal and infectious parasitic are mainly controlled by chemotherapeutics and antibiotics in aquaculture. Nevertheless, the uses of antibiotics and chemotherapy have been strongly criticized as they created problems with drug resistance bacteria, toxicity and accumulation both in fish and the environment. On the contrary, natural products like plant extracts have beneficial effects without any side effects (Citarasu et al., 2002; Sagdic and Ozcan, 2003). Some plants are rich sources of compounds like volatile oils, saponins, phenolic compounds, tannins, alkaloids, polypeptides and polysaccharides. These natural plant products have various activities like antistress, appetizer, antimicrobials and immunostimulants (Citarasu et al., 2002, 2003). Many plant extracts have been investigated for antimicrobial activity in fish. Various research studies have demonstrated that some of these extracts have enormous therapeutic potential. Moreover, they are cheaper, safer, non-toxic, biodegradable and biocompatible. The results of plant extracts controlling bacterial and viral diseases in fish is an encourage for aqua farmers. Out of fourteen herbs tested against Aeromonas hydrophila infection in tilapia (Oreochromis niloticus), the ethanol extract of Psidium guajava has shown good antimicrobial activity (Pachanawan et al., 2008). Similarly, the mixture of methanolic extract of Cynodon dactylon, Aele marmelos, Tinospora cordifolia, Picrorhiza kurroa and Eclipta alba tested successfully against White Spot Syndrome Virus (WSSV) infection in black tiger shrimp, Penaeus monodon(Citarasu, 2006). Following this, the aqueous Azadirachta indica leaf extract showed appreciable result in controlling Aeromonas hydrophila infection in C. carpio (Stasiak and Baumann, 1996; Harikrishnan et al., 2003). Interestingly, Achyranthes aspera seed incorporated in the diet of Labeo rohita has proved that the seed has stimulated immunity and increased resistance to infection in fish (Tan and Vanitha, 2004; Rao et al., 2006). These findings suggest that herbs and their derivatives such as extracts could be an alternative to the chemotherapeutics in aquaculture. The main objective of this study was to determine, the synergistic effect of plant extracts added to diet, on immunological, serum biochemical and blood parameters of Mystus keletius.

\section{Materials And Methods}

Fish: Mystus keletius were obtained from a commercial fish farm at Madurai, India. Before the initiation of the feeding trial, the fish were acclimated to experimental conditions for two weeks by feeding the basal experimental diet (Table 1) without supplementation of the plant extracts. During this time, fish were kept in $50 \mathrm{~L}$ containers with recirculated water and fed at $3 \%$ body weight once daily. 
Synergistic effect of Plant Extracts Supplemented Diets on Immunity and Resistance to Aeromonas

Preparation and testing of the plant extracts for antibacterial activities: Plants species evaluated in this study are shown in Table 1 . Fresh plant parts were washed with deionized water dried at $37^{\circ} \mathrm{C}$ and ground well. Dried plant powders were then soaked in $70 \%$ ethanol (1:1 ratio) individually for 48 hours. The slurry was then filtered with Whattman No. 1 filter paper and centrifuged for $5 \mathrm{~min}$ at $5000 \mathrm{rpm}$. The filtrate obtained from ethanol was evaporated to dryness at $40^{\circ} \mathrm{C}$ in a rotary evaporator and the water extract was then freeze-dried by using a freeze drier system. Finally, the dried extracts were stored at $4^{\circ} \mathrm{C}$ until use. Screening plant extracts for their antibacterial activity against A.hydrophila was conducted using the disc diffusion method as described by Bauer et al. (1966). All tests were replicated three times and zone of inhibition of each extract was measured and recorded (Table 2).

Pathogen: Aeromonas hydrophila (ATCC 49040) was obtained from the Institute of microbial technology, Chandigardh, India. Bacteria were inoculated into $10 \mathrm{ml}$ of liquid tryptic soy broth (TSB, Sigma) medium and were incubated overnight in a shaker for $12 \mathrm{~h}$ at $28^{\circ} \mathrm{C}$. The culture broth was then centrifuged at 3000x g for 10 min. The supernatant was then discarded and the bacterial pellet was washed three times with sterile phosphate buffered saline (PBS, pH 7.2) and prepared to $10^{8} \mathrm{cfu} \mathrm{ml}^{-1}$ as determined using a Neubauer hemocytometer slide. This bacterial suspension was used for further experiments.

Preparation of test diets: The ingredients and proximate compositions of the basal and experimental diets are shown in (Table 1 and 2). Based on the zone of the inhibition (Table 3), Solanum trilobatum and Ocimum sanctum plants were selected for the present study. These two plant extracts in combination were mixed thoroughly (1:1) and incorporated into experimental diets 3,30 and $300 \mathrm{mg} \mathrm{kg}^{-1}$ of dry diet.

Table 1. Composition of basal diet supplemented with herbal immunostimulant

\begin{tabular}{|c|c|c|c|c|}
\hline Composition of basal diet $\mathbf{( g . k g}^{-\mathbf{1}}$ ) & A (control) & B & C & D \\
\hline Fish meal & 290 & 290 & 290 & 290 \\
\hline Soyabean meal & 320 & 320 & 320 & 320 \\
\hline Rice bran & 170 & 170 & 170 & 170 \\
\hline Wheat flour & 130 & 130 & 130 & 130 \\
\hline Fish oil & 60 & 60 & 60 & 60 \\
\hline Vitamin & 15 & 15 & 15 & 15 \\
\hline Minerals & 15 & 15 & 15 & 15 \\
\hline Herbal immunostimulant (mg.kg-1) & $\mathbf{0 . 0}$ & $\mathbf{3 . 0}$ & $\mathbf{3 0 . 0}$ & $\mathbf{3 0 0 . 0}$ \\
\hline Total & 1000 & 1003 & 1030 & 1300 \\
\hline
\end{tabular}

Table 2. Proximate Chemical Composition (g.kg $\left.{ }^{-1}\right)$

\begin{tabular}{|c|c|c|c|c|}
\hline Composition & A (Control) & B & C & D \\
\hline Dry matter & 330 & 308 & 312 & 310 \\
\hline Crude Protein* $^{*}$ & 356 & 388 & 362 & 359 \\
\hline Crude Fat* & 127 & 129 & 127 & 136 \\
\hline Ash & 101 & 113 & 116 & 106 \\
\hline Moisture & 86 & 92 & 83 & 89 \\
\hline
\end{tabular}

Calculated *Crude protein: $35.8 \%$, *Crude fat $-\mathbf{1 2 . 9 8 \% \text { ; }}$

Table 3: List of Plants and their inhibitory activity against A.hydrophila

\begin{tabular}{|c|c|c|c|}
\hline Botanical Name & Family & $\begin{array}{c}\text { Parts used for anti-bacterial } \\
\text { screening }\end{array}$ & Inhibition zone (mm) \\
\hline Solanum trilobatum & Solanaceae & Leaves & 11 \\
\hline Ocimum sanctum & Lamiaceae. & Leaves & 9 \\
\hline
\end{tabular}

Control diet was prepared using the same composition of ingredients except the extract mixture. To prepare the diets, initially, dry ingredients were mixed thoroughly and $1 \%$ of binder was added. Sufficient water along with the oil ingredients were then added to make a paste of each diet. The paste was then cold extruded and pelletized using a hand pelletizer. Finally, the diets were air-dried and stored at $-2^{\circ} \mathrm{C}$ in air tight containers until fed.

Experimental design and feeding: The Fish $(n=600)$ were randomly distributed into 3 experimental groups (B-D) and a control group (A) in triplicate was maintained in 12 tanks (175 L capacity) each containing 50 fish. Group A received the control diet and Groups B, C, D received the diet containing 3, 30,300 extract mixture 
Synergistic effect of Plant Extracts Supplemented Diets on Immunity and Resistance to Aeromonas respectively. The fish were fed thrice a day at 8:00, 13:00 and 18:00 hours at 3\% of the body weight until the end of the experiment. The water quality parameters were monitored every day and maintained at optimal levels by regular water exchange (temperature, $26 \pm 2.0^{\circ} \mathrm{C}$; Dissolved oxygen, $6.1 \pm 0.01 \mathrm{mg} \mathrm{L}^{-1}$; salinity, $0.8 \pm 0.04 \mathrm{ppt}$; $\mathrm{pH}, 6.5 \pm 0.2$; ammonia-nitrogen $<0.26$ ).

Sampling: Every 20 days, $24 \mathrm{~h}$ after final feeding, blood samples were obtained from common cardinal vein of randomly chosen five fish from each tank by using a $1 \mathrm{ml}$ heparinized syringe after they were anesthetized with $100 \mathrm{mg}$ Tricaein methanesulfonate (MS-222) $\mathrm{L}^{-1}$. The blood was then transferred to an Eppendroff tube containing heparin solution, shaken gently and stored in refrigerator at $4^{\circ} \mathrm{C}$. For serum, another five fish from each tank were anaesthetized and blood samples were collected without heparin and allowed to clot for $2 \mathrm{~h}$ at room temperature. The supernatant serum was separated and collected from the remaining blood after centrifugation (2500x g for $15 \mathrm{~min}$ ) and then kept in freezer at $-80^{\circ} \mathrm{C}$ until analysis.

Challenge test: On sixty days after feeding, 35 fish from each group were injected intraperitoneally with 100 $\mu \mathrm{L}$ of live A. hydrophila $\left(1 \times 10^{8} \mathrm{cfu} \mathrm{mL}^{-1}\right)$. Mortality of the challenged fish was noted up to 10 days. The surviving fish were then sampled for serum and blood parameters as per the method described earlier.

Haematology and biochemical indices: For the estimation of leucocyte, erythrocyte counts and haemoglobin concentration, the fresh whole blood samples were used. Red Blood Cell (RBC) and White Blood Cell (WBC) counts were done following the method of Schalm et al. (1975). Haemoglobin (Hb) content of the blood was estimated by Cyanmethaemoglobin method (Varley et al., 1991). Total protein contents and albumin estimations were done following the methods of Lowry et al., (1951) and Wotton and Freeman (1982) respectively. Globulin level was calculated by subtracting albumin level from total protein. For albumin globulin ratio, albumin value was divided by globulin value. Lysozyme activity was determined by the method of Parry et al., (1965) with the slight modification described by Gopalakannan and Arul (2006).

Immunological assays: Bactericidal activity was measured according to the procedure described by Kajita et al. (1990). Respiratory Burst (NBT) activity was measured by the Nitroblue Tetrazolium (NBT) assay. For NBT assay, Secombes (1990) method was followed with modification described by Stasiak and Baumann (1996).

Statistical analysis: All data obtained from experiments were analyzed by a one-way analysis of variance (ANOVA) using the SAS package. Differences between means were determined and compared by Tukey's test. Significance was also set at $5 \%$ level.

\section{RESULTS}

Screening of antimicrobial activity of plant extracts against A. hydrophila was done. Plant extracts showed different degrees of inhibition against A. hydrophila in disc diffusion assay (3). The maximum inhibitory zone was recorded in the order of the Solanum trilobatum and Ocimum sanctum plant extracts.

Haematological analysis: Haemoglobin content was significantly $(\mathrm{p}<0.05)$ higher in group B, C, D at all the assay period as compared to the control group.

Table 3: Effects of herbal supplemented diets on haematological parameters of

Mystus keletius

\begin{tabular}{|c|c|c|c|c|c|}
\cline { 3 - 6 } \multicolumn{2}{c|}{} & \multicolumn{5}{c|}{ Mystus keletius } \\
\hline Parameters & Group & $\mathbf{2 0}$ & $\mathbf{4 0}$ & $\mathbf{6 0}$ & $\mathbf{7 0}$ \\
\hline \multirow{4}{*}{$\begin{array}{c}\text { Haemoglobin } \\
\text { (g\%) }\end{array}$} & $\mathrm{A}$ & $7.8 \pm 0.14$ & $8.3 \pm 0.24$ & $8.8 \pm 0.61$ & $9.0 \pm 0.76$ \\
\cline { 2 - 6 } & $\mathrm{B}$ & $8.3 \pm 0.14$ & $8.6 \pm 0.45$ & $9.3 \pm 0.32$ & $9.6 \pm 1.16$ \\
\cline { 2 - 6 } & $\mathrm{C}$ & $8.6 \pm 0.14$ & $8.9 \pm 0.12$ & $9.6 \pm 0.78$ & $9.9 \pm 2.16$ \\
\cline { 2 - 6 } & $\mathrm{D}$ & $9.3 \pm 0.14$ & $9.5 \pm 0.96$ & $9.9 \pm 1.16$ & $10.2 \pm 0.64$ \\
\hline \multirow{3}{*}{$\begin{array}{c}\text { White Blood Cells } \\
\text { x 103. } \text { mm }^{3}\end{array}$} & $\mathrm{~A}$ & $32.64 \pm 0.14$ & $38.12 \pm 0.87$ & $43.10 \pm 2.43$ & $47.65 \pm 0.32$ \\
\cline { 2 - 6 } & $\mathrm{B}$ & $34.68 \pm 0.14$ & $40.98 \pm 1.24$ & $48.12 \pm 1.95$ & $53.24 \pm 0.19$ \\
\cline { 2 - 6 } & $\mathrm{C}$ & $36.74 \pm 0.14$ & $43.14 \pm 2.40$ & $52.10 \pm 2.76$ & $59.13 \pm 0.54$ \\
\cline { 2 - 6 } & $\mathrm{D}$ & $42.95 \pm 0.14$ & $48.10 \pm 0.68$ & $59.10 \pm 2.98$ & $65.12 \pm 0.38$ \\
\hline \multirow{3}{*}{$\begin{array}{c}\text { Red Blood Cells } \\
\text { (x 10 4. mm }\end{array}$} & $\mathrm{A}$ & $1.6 \pm 0.14$ & $1.8 \pm 0.86$ & $2.2 \pm 3.09$ & $2.5 \pm 1.16$ \\
\cline { 2 - 6 } & $\mathrm{B}$ & $1.8 \pm 0.14$ & $2.3 \pm 0.09$ & $2.7 \pm 0.13$ & $2.9 \pm 2.10$ \\
\cline { 2 - 6 } & $\mathrm{C}$ & $1.9 \pm 0.14$ & $2.5 \pm 0.35$ & $2.9 \pm 0.76$ & $3.4 \pm 1.46$ \\
\cline { 2 - 6 } & $\mathrm{D}$ & $2.1 \pm 0.14$ & $2.9 \pm 0.24$ & $3.5 \pm 0.54$ & $3.9 \pm 0.96$ \\
\hline
\end{tabular}

Values are expressed as Mean \pm S.D; 
Synergistic effect of Plant Extracts Supplemented Diets on Immunity and Resistance to Aeromonas

Table 4. Effects of Herbal extracts supplemented diet on Mystus keletius

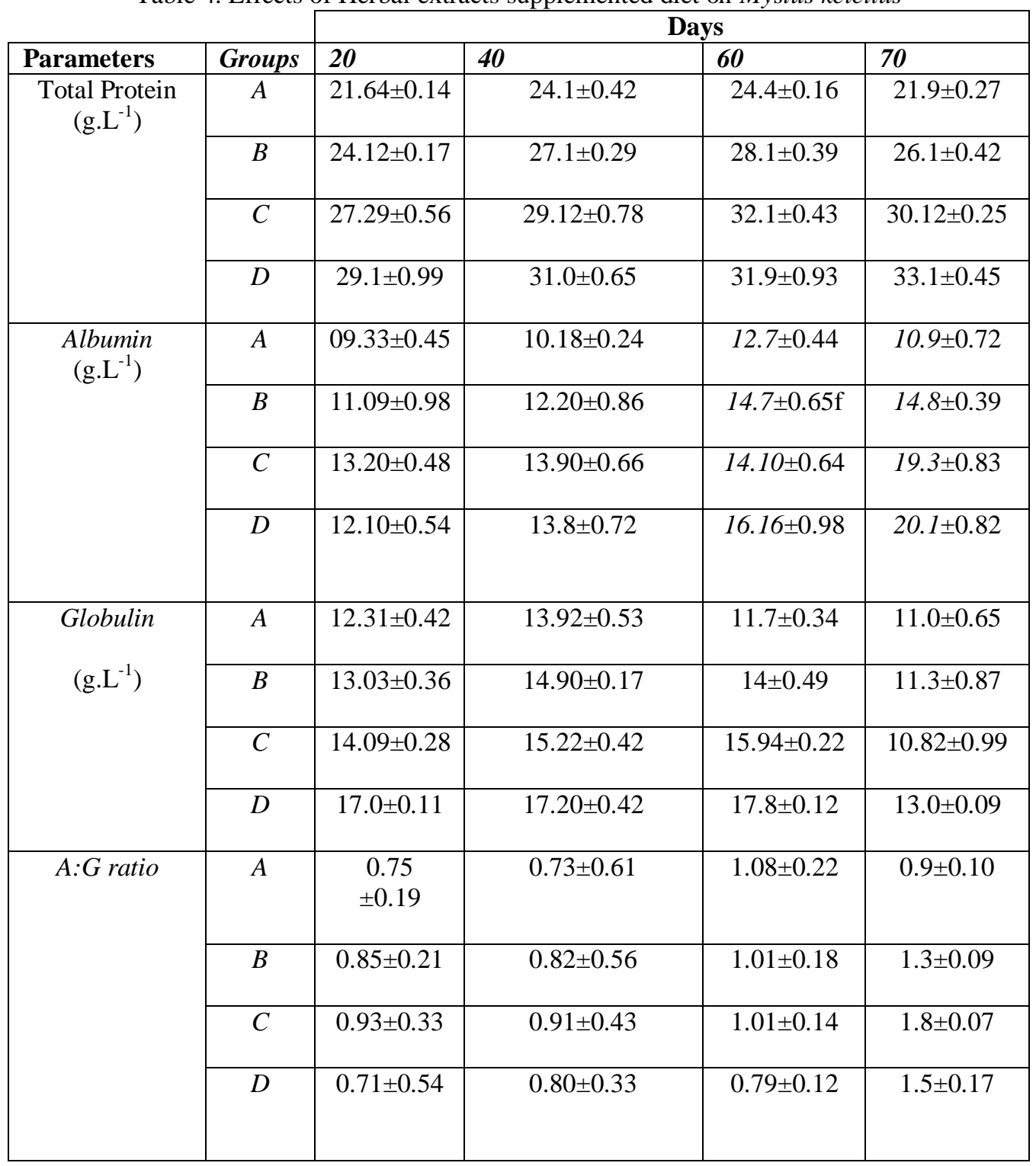

Values are expressed as Mean \pm S.D.

Moreover, the difference among $\mathrm{B}, \mathrm{C}$ and $\mathrm{D}$ was significant $(\mathrm{p}<0.05)$. At all the assay periods, a gradual significant increase of WBC count $(\mathrm{p}<0.05)$ was observed maximum in group D than in group B and C (Table 3). Similarly, RBC counts have shown enhancing trend in all the experimental groups. The highest significant RBC level $(p<0.05)$ was observed in group D on 20, 40, 60 and post-challenge period (day 70 ).

Biochemical parameters: The total protein level increased in all experimental groups compared with the control group (Table 4). The maximum level of total protein was recorded in group D for all the assay duration. Similarly, albumin and globulin content was significantly $(\mathrm{p}<0.05)$ higher in group D as compared to other groups on different assay days. Albumin globulin ratio presented in this study also exhibited significant difference in the treatment group $(\mathrm{p}<0.05)$ over the control group during the experiment (Table 4).

Immunological assay: The results of the serum bactericidal activity are shown in Fig. 1. Bactericidal activity in the four experimental groups was significantly $(\mathrm{p}<0.05)$ higher than control group at all the assay periods including post-challenge ( Fig.1). In addition, the highest level of bactericidal activity was observed in group D. Nevertheless, the bactericidal activity in D was highest and the difference between D and C, D and B was found to statistically significant $(\mathrm{p}<0.05)$. 


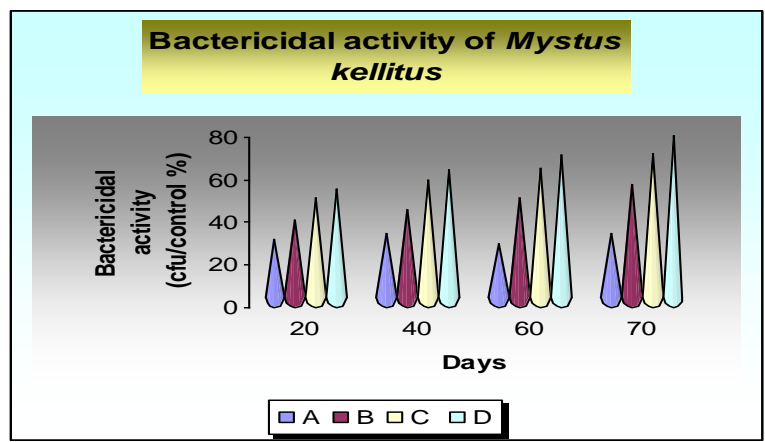

Fig.1. Bactericidal activity (cfu/control) of Mystus keletius fed on herbal diet (B-D) and control diet (A). Values are expressed as Mean \pm SD.

Likewise, the respiratory Burst (NBT) activity also showed an increasing trend from A (control group) to D in all assay periods and as well as after challenge (Fig. 2).

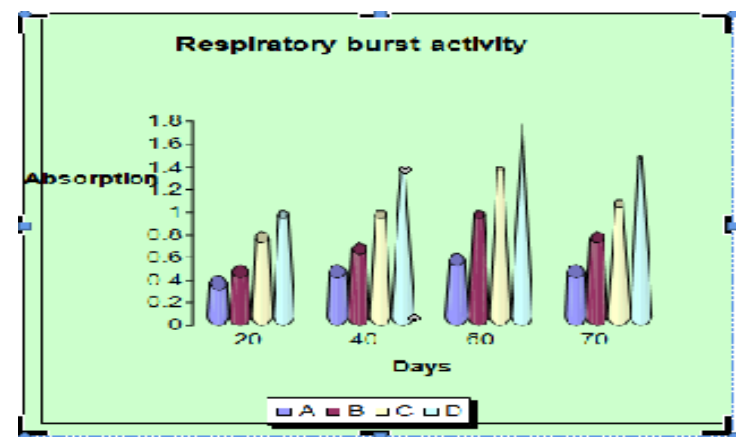

Fig. 2. Respiratory burst (NBT) activity of Mystus keletius, fed on herbal diets.

Values are expressed as Mean \pm SD.

In all the treatments, a gradual significant increase of lysozyme activity $(\mathrm{p}<0.05)$ was observed which reached a maximum in group D at all assay periods including post-challenge (Fig. 3)

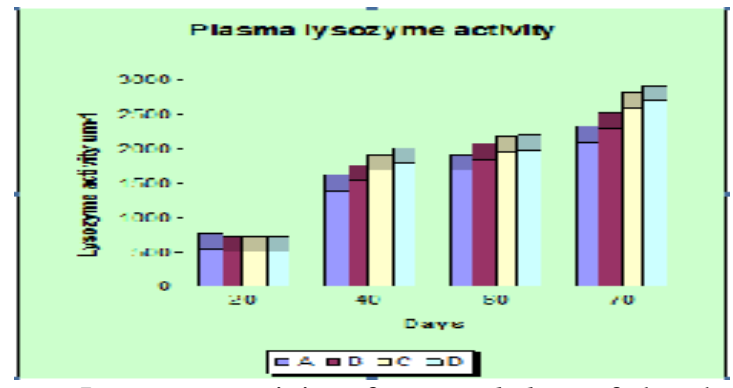

Fig.3. Plasma Lysozyme activity of Mystus keletius fed on herbal diets

Values are expressed as Mean \pm S.D..

Challenge study: The mortalities of the challenged fish were observed from the first day post-challenge. After day 8 there was no mortality up to day 10 . The survival percentage was found to be highest $(85.71 \%)$ in the group D followed by group C (80.95\%) B (72.15\%) and lowest (38.09\%) in control group (Fig. 4).

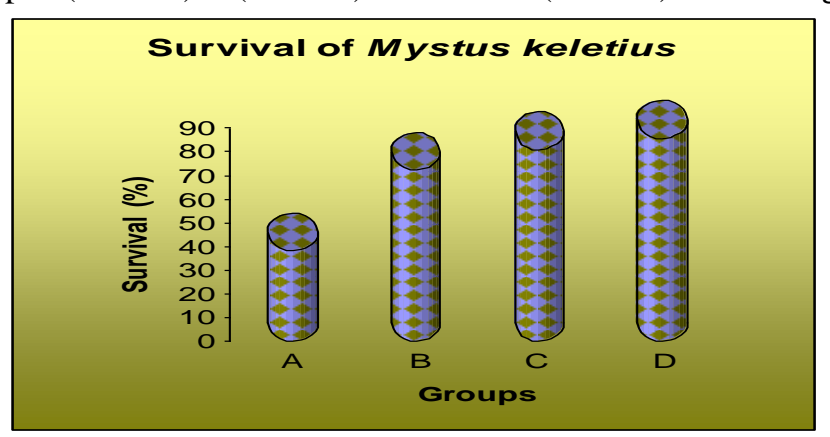

Fig.4. Survival rate of Mystus keletius fed on herbal extract supplemented diets 


\section{Discussion}

The present study projects the impact of the mixture of plant extracts on the haematological and immunological responses in Mystus keletius. This finding is quite matching with the work of Ardo et al., 2008 stating that plant extracts act as immuno-stimulants enhancing non-specific immune system of cultured fish species.

The haematological parameters such as Haemoglobin, WBC and RBC counts in the present investigation were significantly higher in extract mixture supplemented diets over control group. This is in agreement with the work of Sahu et al., (2007) who reported that WBC and RBC counts were higher in Labeo rohita fingerlings fed Mangifera indica kernel when compared to control. Further, these observations also vouches the finding of Gopalakannan and Arul (2006), who reported that there was an increase in the WBC count after feeding the common carp with chitin.

The plant extracts in mixture used in this study could enhance total plasma protein, albumin and globulin values in treatment groups compared to control group. Similar results were reported in Roghu fingerlings (Labeo rohita) fed with Achyranthes aspera seed (Sivaram et al., 2004; Rao et al., 2006) ; L. rohita fingerlings fed with Mangifera indica kernel (Sahu et al., 2007). Since serum proteins include various humoral elements of the non-specific immune system, measurable total protein, albumin and globulin levels suggest that high concentrations are likely to be a result of the enhancement of the non-specific immune response of fishes.

In comparison with control group, serum bactericidal activity was significantly increased in all experimental groups of this study. This revealed that the immunostimulant herbals incorporated diets helped to increase the humoral elements in the serum. This is in agreement with the finding of Sivaram et al. (2004) in juvenile greasy groupers (Epinphelus tauvina) fed with Ocimum sanctum and Withania somnifera and in grouper (E. tauvina) juveniles fed with herbal plants mixture diet (Shao et al., 2004).

An enhancement of respiratory burst activity in Mystus keletius has been identified in this work. This finding gets the support from the work of Gopalakannan and Arul (2006) who reported that dietary supplementation of chitosan; chitin and levamisole significantly $(\mathrm{p} \leq 0.001)$ enhanced NBT reduction in $C$. carpio. Further, herbal based immunostimulants enhancing the respiratory burst activity in fish has been well documented; Magnifera indica (mango) kernel as a feed additive increased the superoxide anion production in Labeo rohita fingerlings (Yadava et al., 1992; Shao et al., 2004; Sahu et al., 2007), two herbal extracts (Astragalus membranaceus and Lonicera japonica) alone or in combination also significantly enhanced phagocytic and respiratory burst activity of blood phagocitic cells in Oreochromis mossambicus (Ardo et al.,2008), Achyranthes aspera seed fed Labeo rohita has shown a substantial production of superoxide anion (Seacombes and Fletcher, 1992; Rao et al., 2006). This action could be due to the enlightening immune response by a suitable immunostimulant.

In this study an increasing trend in lysozyme activity has been projected. Several reports indicating the role of immunostimulants in enhancing lysozyme activity has been documented. The level of serum lysozyme was enhanced in Labeo rohita fed with Achyranthes aspera seed (Rao et al., 2006), in Japanese eel (Anguilla japonica) fed with Korean mistletoe extract (KM-110; Viscum album Coloratum) (Choi et al., 2008), in carp fed with four Chinese herbs (Rheum officinale andrographis paniculata, Isatis indigotica, Lonicera japonica) (Chen et al., 2003). The increasing trend could be due to lysozyme, a humoral component of the non-specific defense mechanism, that has the ability to prevent the growth of infectious microorganism by splitting $\beta-1,4$ glycosidic bonds between $\mathrm{N}$-acetylmuramic acid and $\mathrm{N}$-acetylglucosamine in the peptidoglycan of bacterial cell walls (Seacombes, 1996; Choi et al., 2008).

Interestingly, after challenge with A. hydrophila, all the experimental groups showed higher survival rate compared to the control. This might be due to the enhancement of the non-specific immune system of fish by plant extracts. Similar results were reported after feeding Labeo rohita fingerlings with Mangifera indica kernel and challenged with A. hydrophila (Schaperclaus,1992; Sahu et al., 2007). Pachanawan et al., (2008) also reported Psidium guajava or ethanol extract of $P$. guajava leaf fed Oreochromis niloticus when challenged with A. hydrophila has shown enhanced survival rates. Likewise, Ardo et al., (2008) also reported that feeding tilapia (Oreochromis niloticus) with two Chinese medicine herbs reduced mortality when the fish were experimentally infected with $A$. hydrophila.

\section{Conclusion}

In conclusion, plant leaf extracts in combination rather than alone used in this study considerably has enhanced the non- specific, specific immunity and increased disease resistance of Mystus keletius. In addition, the underlying molecular mechanism beside the isolation and characterization of the active compounds from these plants require more study. 


\section{Acknowledgement}

The researchers are thankful to the management of both colleges, Yadava College, Madurai and M.S.S.Wakf Board College, Madurai for their strong support in carrying out this research.

\section{References}

[1] Ardo, L., G. Yin, P. Xu, L. Varadi, G. Szigeti, Z. Jeney and G. Jeney, 2008. Chinese herbs (Astragalus membranaceus and Lonic era japonica) and boron enhance the non-specific immune response of Nile tilapia (Oreochromis niloticus) and resistance against Aeromonas hydrophila. Aquaculture, 275: 26-33.

[2] Chen, X., Z. Wu, J. Yin and L. Li, 2003. Effects of four species of herbs on immune function of Carassius auratus gibelio. J. Fish Sci. China, 10: 36-40.

[3] Choi, S.H., K.H. Park, T.J. Yoon, J.B. Kim, Y.S. Jang and C.H. Choe, 2008. Dietary Korean mistletoe enhances cellular nonspecific immune responses and survival of Japanese eel (Anguilla japonica). Fish Shellfish Immunol., 24: 67-73.

[4] Citarasu, T., K. Venkatramalingam, M.M. Babu, R.R.J. Sekar and M. Petermarian, 2003. Influence of the antibacterial herbs, Solanum trilobatum andrographis paniculata and Psoralea corylifolia on the survival, growth and bacterial load of Penaeus monodon post larvae. Aquac. Int., 11: 581-595.

[5] Citarasu, T., M.M. Babu, R.J.R. Sekar and P.M. Marian, 2002. Developing Artemia enriched herbal diet for producing quality larvae in Penaeus monodon, Fabricius. Asian Fish Sci., 15: 21-32.

[6] Farag, R.S., Z.Y. Dawz, F.M. Hewedi and G.S. El-Barotyl, 1989. Antimicrobial activity of some Egyptian Spice essential oils. J. Food Prot., 52: 665-667.

[7] Gopalakannan, A. and V. Arul, 2006. Immunomodulatory effects of dietary intake of chitin, chitosan and levamisole on the immu ne system of Cyprinus carpio and control of Aeromonas hydrophila infection in ponds. Aquaculture, 255: 179-187.

[8] Harikrishnan, R., R.M. Nisha and C. Balasundaram, 2003. Hematological and biochemical parameters in common carp, Cyprinus carpio, following herbal treatment for Aeromonas hydrophila infection. Aquaculture, 222: 41-50.

[9] Lowry, O.H., N.J. Rosebrough, A.L. Farr and R.J. Randall, 1951. Protein measurement with Folin phenol reagent. J. Biol. Chem., 193: 265-275.

[10] Pachanawan, A., P. Phumkhachorn and P. Rattanachaikunsopon, 2008. Potential of Psidium guajava supplemented fish diets in controlling aeromonas hydrophila infection in tilapia (Oreochromis niloticus). J. Biosci. Bioeng., 106: 419-424.

[11] Parry, R.M., R.C. Chandau and K.M. Shahani, 1965. A rapid and sensitive assay of muramidase. Proc. Soc. Exp. Biol. Med., 119: 384-386.

[12] Rao, Y.V., B.K. Das, J. Pradhan and R. Chakrabarti, 2006. Effect of Achyranthes aspera on the immunity and survival of Labeo rohita infected with Aeromonas hydrophila. Fish Shellfish Immunol., 20: 263-273.

[13] Sagdic, O. and M. Ozcan, 2003. Antibacterial activity of Turkish spice hydrosols. Food. Control, 14: $141-143$.

[14] Sahu, S., B.K. Das, J. Pradhan, B.C. Mohapatra, B.K. Mishra and N. Sarangi, 2007. Effect of Magnifera indica kernel as a feed additive on immunity and resistance to Aeromonas hydrophila in Labeo rohita fingerlings. Fish Shellfish Immunol., 23: 109-118.

[15] Schalm, O.W., N.C. Jain and G.H. Carroll, 1975. Veterinary Haematology. 3rd Edn., Lea and Febiger, Philadelphia, PA, USA.

[16] Schaperclaus, W., H. Kulow and K. Schreckenbach, 1992. Fish Disease. A.A. Balkema, Rotterdam, The Netherlands.

[17] Secombes, C.J. and T.C. Fletcher, 1992. The role of phagocytes in the protective mechanisms of fish. Annu. Rev. Fish Dis., 2: 5371.

[18] Secombes, C.J., 1990. Isolation of Salmonid Macrophages and Analysis of their Killing Activity. In: Techniques of Fish Immunology, Stolen, J.S., T.C. Fletcher, D.P. Anderson, B.S. Roberson and W.B. van Muiswinkel (Eds.). Vol. 1, SOS Publication s, Fair Haven, NJ., pp: 137-154.

[19] Secombes, C.J., 1996. The Non-Specific Immune System: Cellular Defenses. In: The Fish Immune System: Organism, Pathogens and Environment, Iwama, G. and T. Nakanishi (Eds.). Academic Press, San Diego, CA, pp: 63-103.

[20] Shao, B.M., W. Xu, H. Dai, P. Tu, Z. Li and X.M. Gao, 2004. A study on the immune receptors for polysaccharides from the roots of Astragalus membranaceus, a Chinese medicinal herb. Biochem. Biophys. Res. Commun., 320: 1103-1111.

[21] Sivaram, V., M.M. Babu, G. Immanuel, S. Murugadass, T. Citarasu and M.P. Marian, 2004. Growth and immune response of juvenile greasy groupers (Epinephelus tauvina) fed with herbal antibacterial active principle supplemented diets against Vibrio harveyi infections. Aquaculture, 237: 9-20.

[22] Stasiak, A.S. and C.P. Baumann, 1996. Neutrophil activity as a potential bioindicator for contaminant analysis. Fish Shellfish Immunol., 6: 537-539.

[23] Tan, B.K.H. and J. Vanitha, 2004. Immunomodulatory and antimicrobial effects of some traditional Chinese medicinal herbs: A review. Curr. Med. Chem., 11: 1423-1430.

[24] Varley, H., A.H. Gowenblock and M. Bell, 1991. Practical Clinical Biochemistry. 5th Edn., Vol. 1, CBS Publication and Distributors, Delhi, India, pp: 479-480.

[25] Wotton, I.D. and H. Freeman, 1982. Microanalysis in Medical Biochemistry. Churchill, New York, USA.

[26] Yadav, M., G. Indira and A. Ansary, 1992. Cytotoxin elaboration by Aeromonas hydrophila isolated from fish with epizootic ulcerative syndrome. J. Fish Dis., 15: 183-189. 